\title{
De pandemias, literatura y academia
}

\author{
About pandemics, literature and academy
}

Robin G. Prieto 0., MD ${ }^{*}$

\author{
Especialista en Gastroenterología y Endoscopia \\ Digestiva. Hospital Central de la Policía HOCEN. \\ Centro de Enfermedades Hepáticas y Digestivas \\ CEHYD SAS. Bogotá D.C., Colombia. \\ *Correspondencia: Robin G. Prieto 0. \\ rgprietoo@hotmail.com \\ Fecha recibido: $15 / 04 / 20$ \\ Fecha aceptado: $18 / 04 / 20$
}

Históricamente, el arte se clasificó de acuerdo con las sensaciones logradas por los cinco sentidos: las percibidas por el gusto, el olfato y el tacto se consideraron artes menores, mientras que las percibidas por el oído y la vista fueron consideradas las artes mayores, o bellas artes. Aunque a partir de 1911 oímos hablar del "séptimo arte", los griegos consideraban seis artes clásicas o bellas artes: arquitectura, escultura, pintura, declamación, música y danza. Desde hace ya varios siglos, se ha incluido a la poesía y a la literatura como parte de la declamación, siendo entonces considerada la literatura como parte de las bellas artes.

En esta difícil época, todos hemos vuelto a oír de las pandemias, pero esta no es ni una palabra nueva, ni una situación nueva. Los historiadores, los literatos o simplemente los amantes de la lectura saben que a lo largo de la historia son muchos los libros que relatan o describen estas difíciles etapas para la humanidad.

La peste negra (1347-1351) es considerada como la pandemia que más muertos ha causado en el planeta (200 millones). Se cree que se originó en China, fue llevada a Europa en las rutas mercantes, y que fue transmitida a los humanos por las pulgas de las ratas. La medicina de la época era muy empírica y se basaba especialmente en observaciones; quizás una de las más importantes fue la que notó que, las pocas personas que sobrevivían en los barcos anclados en los puertos por muchos días, lo hacían después de cuarenta días, es de allí de donde surge el término cuarentena. Actualmente se considera que la bacteria Yersinia pestis fue la causante de esta pandemia. Quizás la obra literaria más representativa sobre este suceso es El Decamerón, libro publicado en 1353 por Giovanni Boccaccio (1313-1375), escritor italiano quien vivió gran parte de su vida en Florencia, una de las ciudades más devastada por la peste negra.

Se considera a la viruela (milenios a. de C.-1980) como la segunda enfermedad que ha causado más muertes en el mundo ( 56 millones). Esta fue causada por el Variola virus y estuvo presente en el planeta desde hace miles de años. A lo largo de los siglos se presentó como una epidemia que atacó a la antigua Atenas, diezmó dramáticamente la población indígena en la "conquista americana", y causó más de 400000 muertes por año en las primeras décadas del siglo XIX en Europa. El médico inglés Edward Jenner (1749-1823) es considerado el padre de la inmunología y fue quien en 1796 descubrió la vacuna contra la viruela $(1,2)$; esta infección fue considerada por la Organización Mundial de la Salud (OMS) como erradicada desde 1980. La escritora española María Solar publicó en 2017 su libro Los niños de la viruela, obra de ficción ambientada en 1803, que se basa en hechos reales, y destaca al personal médico y a los niños de la época. 
El primer caso conocido de la gripe española (19181920) ocurrió el 4 de marzo de 1918, en Fort Riley (Kansas, Estados Unidos). Esta pandemia fue causada por un virus que mutó en agosto del mismo año, propagando la infección al puerto francés de Brest, de donde pasó a Inglaterra, Italia, Alemania y, finalmente, a España, país declarado neutral en aquella época de la Primera Guerra Mundial. España no censuró las noticias respecto a la enfermedad, hecho que sí ocurrió en las dos líneas de combate en el resto del mundo. Informes iniciales indican que murieron entre 40 y 50 millones de personas, por lo que es considerada la tercera pandemia en número total de muertos, aunque algunos cálculos recientes mencionan entre 50 y 100 millones de muertos (3). La pandemia ocurrió en tres oleadas de infección, pero fue la segunda (finales de 1918) la que cobró más vidas. Los médicos de la época recomendaron diversos tratamientos con aguas medicinales a base de plantas, además de quinina y dosis elevadas de aspirina. En 1943 se descubrió que el virus causante fue la cepa Influenza A del subtipo $\mathrm{H}_{1} \mathrm{~N}_{1}$ y que a diferencia de otras epidemias de gripe, en esta, la mayoría de las víctimas fueron los jóvenes y adultos saludables (4). Colombia también se vio afectada por la gripe española (Figura 1), pero a diferencia del mundo y de acuerdo con investigaciones realizadas a finales del siglo pasado, no ocurrieron las tres oleadas de infección; la mayor altura sobre el nivel del mar fue un factor de riesgo de mortalidad, la cual ocurrió en número aproximado de 3000 , especialmente en el departamento de Boyacá $(5,6)$. Con relación a esta pandemia, vale la pena destacar el ensayo histórico "El jinete pálido: la epidemia que cambió el mundo" (2018) de la periodista científica inglesa Laura Spinney.

La actual Estambul fue el epicentro de la cuarta plaga que más vidas ha cobrado. El Imperio romano de Oriente estaba en su apogeo y la ciudad de Constantinopla, capital del Imperio bizantino, liderada por el emperador Justiniano, sufrió la plaga de Justiniano (541-542). Se considera que la epidemia se originó probablemente en Tanzania, de donde pasó a Egipto, luego a Europa y, finalmente, a Asía. La causa más aceptada de la pandemia es la peste bubónica, causada por Yersinia pestis, bacteria transmitida por la pulga de la rata negra, como ya se mencionó. Los registros mencionan que las únicas medidas sanitarias tomadas fueron las leyes promulgadas por el emperador, quien ordenó inicialmente la acumulación de los cuerpos en barcos que luego eran enviados a la deriva en el mar, y posteriormente el entierro de todos los cuerpos en grandes fosas comunes; se calcula que ocurrieron entre $30 \mathrm{y}$ 50 millones de muertes. En el año 2007, el historiador norteamericano Lester Little publicó su obra Plague and

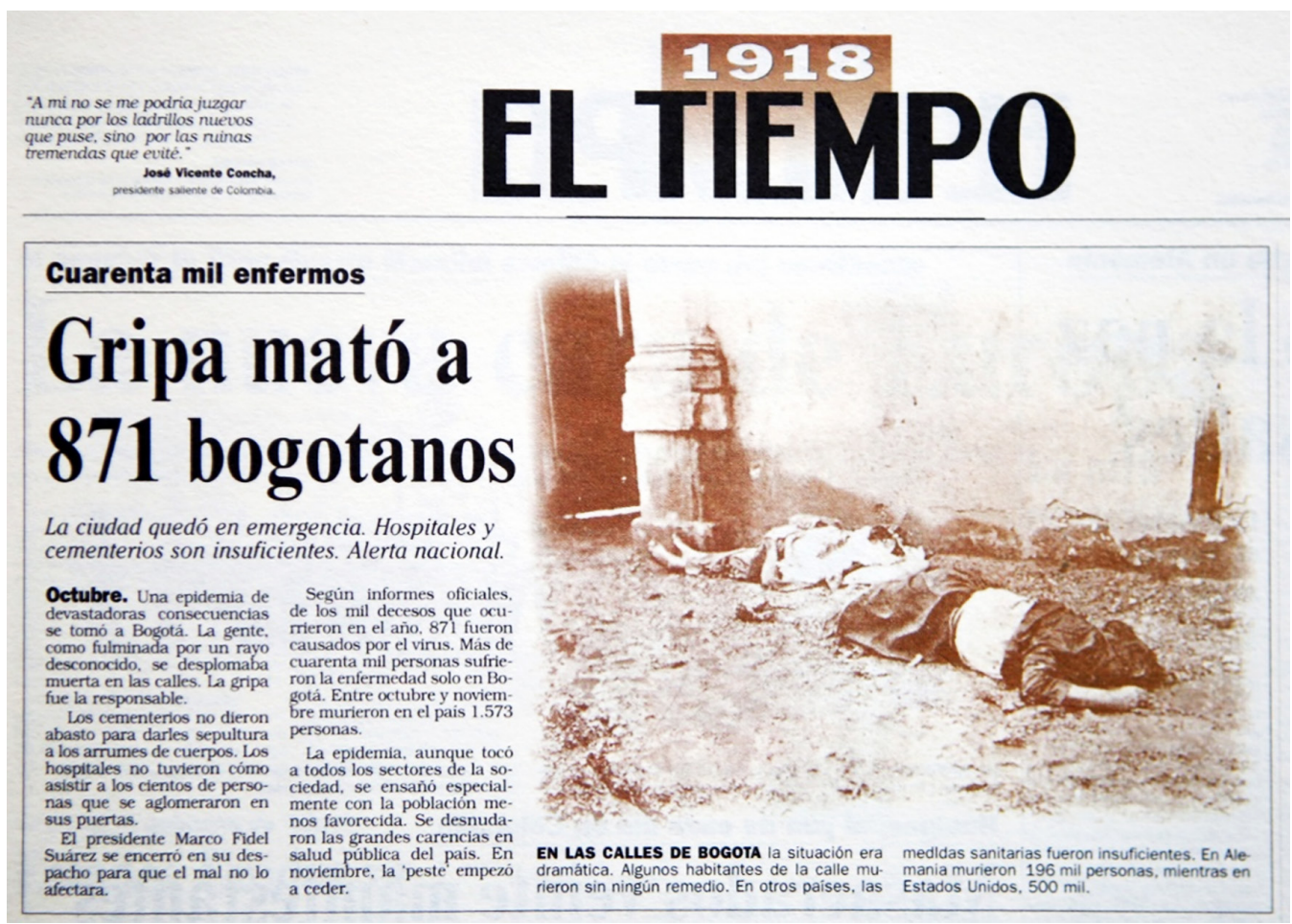

Figura 1. Facsímil de El tiempo de 1918. Tomada de: https://files.rcnradio.com/public/2018-10/facsimil_el_ tiempo_1918_0.jpg 
the end of the antiquity: The Pandemic of 541-750, en la que describe la pandemia en relación con la caída del Imperio romano y el surgimiento del Imperio árabe (7).

El puesto número cinco dentro de las pandemias que más muertes han cobrado en la historia de la humanidad es ocupado actualmente por el VIH-SIDA (1981-actualidad). Es causada por el virus de la inmunodeficiencia humana (de la familia de los retrovirus), que es transmitido por la sangre, el semen y los fluidos vaginales, cuyo origen se ha localizado en África Central, en algunas subespecies de chimpancés. De acuerdo con la OMS, esta pandemia ha causado más de 32 millones de muertes en todo el mundo (8). Por ser una pandemia reciente, la literatura está llena de exponentes que tratan este tema; por ejemplo, en 1990, la escritora y periodista francesa Dominique Lapierre publicó su libro Más grandes que el amor, en el que relata los dramas relacionados con la pandemia a comienzos de la década de 1980.

La historia de la literatura ha visto la publicación de muchas novelas relacionadas con las epidemias y pandemias, entre las que se encuentran La peste (1947) de Albert Camus y El amor en los tiempos del cólera (1985), en la que García Márquez plasma su realismo mágico. Asimismo, se han escrito muchos otras obras consideradas de ciencia ficción, pero que no distan mucho de la realidad: El último hombre (1826) de Mary Shelley, La peste escarlata (1912) de Jack London, Epidemia (1987) de Robin Cook, Ensayo sobre la ceguera (1995) de José Saramago, y El año de la plaga (2018) de Marc Pastor, entre muchas otras. Todos estos libros muestran la fragilidad del ser humano a pesar de creernos poseedores de la ciencia, del conocimiento y de la tecnología, pero también resaltan el esfuerzo de los investigadores, del personal médico y de la salud para salvar a la humanidad, incluso a costa de sus propias vidas.

Al buscar el significado la palabra academia, encuentro que significa "institución oficial constituida por personas destacadas en las letras, las artes o las ciencias, que realizan colectivamente determinadas actividades"; los médicos, además de cumplir con el juramento hipocrático, por supuesto con todas las garantías, tenemos también el deber y la capacidad de aportarle al mundo otra literatura, la literatura médica, especialmente en estos tiempos de pandemia en los que a 6 de abril de 2020, el COVID-19 ha cobrado la vida de 75945 personas y amenaza con ser una de las pandemias más letales de la historia.

Pronto el séptimo arte desplegará de nuevo su capacidad y veremos muchas películas y leeremos muchas más obras de ficción acerca de la pandemia que hoy nos toca. Sin embargo, lo que ahora vivimos no es ciencia ficción, es nuestra realidad, una realidad llena de temores, de nuevos retos, y seguramente de éxitos. Me viene a la memoria nuestra historiadora Diana Uribe, quien en su capítulo "Literatura en tiempos de pandemia" nos recalca lo que siempre hemos sabido, y es que... "el ser humano ha sobrevivido por el apoyo, no por la competencia” (9).

\section{REFERENCIAS}

1. Iglesias-Gamarra A, Siachoque H, Pons-Estel B, Restrepo JF, Quintana LG, Gómez Gutiérrez A. Historia de la autoinmunidad. Primera Parte La inmunología ¿desde dónde y hacia dónde? Rev. Colomb. Reumatol. 2009;16(1):11-31.

2. Jenner E. History of the Inoculation of the Cow-Pox: Further Observations on the Variole Vaccince, or Cow-Pox. Med Phys J. 1799;1(4):313-318.

3. Duncan KE. Hunting the 1918 Flu: One Scientist's Search for a Killer Virus. Toronto: University of Toronto Press; 2003. p. 297.

4. Biblioteca Nacional de España. La gripe española: la mayor pandemia de la historia moderna. [video]. España: BNEscolar; 2019. Disponible en: https://www.youtube. com/watch?v=si6IkKSLYZE

5. Ospina J, Martínez A, Herrán O. Impacto de la pandemia de gripa de 1918-1919 sobre el perfil de mortalidad general en Boyacá, Colombia. História, Ciências, Saúde. 2009; 16(1):53-81.

6. Manrique F, Martínez A, Meléndez B, Ospina J. La pandemia de gripe de 1918-1919 en Bogotá y Boyacá, 91 años después. Infectio. 2009;13(3):182-91.

7. Little LK. Plague and the end of the antiquity: The Pandemic of 541-750. Nueva York: Cambridge University Press; 2007.p. 360.

8. Organización Mundial de la Salud [sede Web]. OMS; 2019 [actualizado 15 de noviembre de 2019; acceso 21 de abril de 2020]. VIH/sida. Disponible en: https://www.who.int/es/ news-room/fact-sheets/detail/hiv-aids

9. DianaUribe.fm [sede Web]. Diana Uribe; 2020 [actualizado 21 de marzo de 2020; acceso 21 de abril de 2020]. Literatura en tiempos de Pandemia. Disponible en: https://www.dianauribe.fm/especiales/literatura-en-tiempos-de-pandemia

\section{LECTURAS RECOMENDADAS}

- Gaceta Médica [sede Web]. Gaceta Médica; 2018 [actualizado 19 de enero de 2018: acceso 21 de abril de 2020]. De Pulido S. La Gripe Española: la pandemia de 1918 que no comenzó en España. Disponible: https://gacetamedica. com/investigacion/la-gripe-espanola-la-pandemia-de1918-que-no-comenzo-en-espana-fy1357456/

- Infobae [sede Web]. Infobae; 2020 [actualizado 18 de marzo de 2020; acceso 21 de abril de 2020]. De la peste negra al coronavirus: cuáles fueron las pandemias más letales de la historia. Disponible en: https://www.infobae.com/america/ mundo/2020/03/18/de-la-peste-negra-al-coronavirus-cuales-fueron-las-pandemias-mas-letales-de-la-historia/

- Lit2Go [sede Web]. Lit2Go [acceso 21 de abril de 2020] De Jenner EA. A Continuation Of Facts And Observations Relative To The Various Vaccines, Or Cow-Pox, 1800. Disponible en: https://etc.usf.edu/lit2go/51/on-vaccination-againstsmallpox/988/a-continuation-of-facts-and-observations-relative-to-the-various-vaccines-or-cow-pox-1800/ 